\title{
Mitochondrial Dysfunction: Different Routes to Alzheimer's Disease Therapy
}

\author{
Pasquale Picone, Domenico Nuzzo, Luca Caruana, Valeria Scafidi, and Marta Di Carlo
}

Istituto di Biomedicina ed Immunologia Molecolare (IBIM) "Alberto Monroy," CNR, via Ugo La Malfa 153, 90146 Palermo, Italy

Correspondence should be addressed to Marta Di Carlo; marta.dicarlo@ibim.cnr.it

Received 19 March 2014; Accepted 29 May 2014; Published 20 August 2014

Academic Editor: Giles E. Hardingham

Copyright (c) 2014 Pasquale Picone et al. This is an open access article distributed under the Creative Commons Attribution License, which permits unrestricted use, distribution, and reproduction in any medium, provided the original work is properly cited.

Mitochondria are dynamic ATP-generating organelle which contribute to many cellular functions including bioenergetics processes, intracellular calcium regulation, alteration of reduction-oxidation potential of cells, free radical scavenging, and activation of caspase mediated cell death. Mitochondrial functions can be negatively affected by amyloid $\beta$ peptide (A $\beta$ ), an important component in Alzheimer's disease (AD) pathogenesis, and $\mathrm{A} \beta$ can interact with mitochondria and cause mitochondrial dysfunction. One of the most accepted hypotheses for AD onset implicates that mitochondrial dysfunction and oxidative stress are one of the primary events in the insurgence of the pathology. Here, we examine structural and functional mitochondrial changes in presence of $\mathrm{A} \beta$. In particular we review data concerning $\mathrm{A} \beta$ import into mitochondrion and its involvement in mitochondrial oxidative stress, bioenergetics, biogenesis, trafficking, mitochondrial permeability transition pore (mPTP) formation, and mitochondrial protein interaction. Moreover, the development of AD therapy targeting mitochondria is also discussed.

\section{Introduction}

Alzheimer's disease (AD) is an age-related progressive neurodegenerative disorder characterized by impairment of cognitive function. The neuropathology of $\mathrm{AD}$ concerns two neurodegenerative processes: amyloidogenesis, leading to the presence of extracellular amyloid $\beta$-peptide $(\mathrm{A} \beta)$ deposition, and neurofibrillary degeneration, corresponding to the formation of intracellular tangles composed of phosphorylated Tau protein [1]. The presence of these abnormal structures leads to neuronal dysfunction and cell death. Many lines of evidence suggest that the mitochondrion plays a central role in neurodegenerative diseases, including $\mathrm{AD}$ [2], and the so called mitochondrial cascade hypothesis proposes that mitochondrial dysfunction is the primary event in $\mathrm{AD}$ pathology [3]. Mitochondrion is a cellular organelle required for bioenergetics processes and is also involved in aminoacid, lipid, and steroid metabolism, calcium homeostasis, free radicals production, and apoptosis triggering. In the brain, where there is the highest energy request and consumption, the number of mitochondria is elevated mainly in the synapses and impairment could be a serious threat for neurons survival.

Many aspects of the strict link between mitochondrial dysfunction and $\mathrm{AD}$ remain to be elucidated, but some evidence indicates that the progressive accumulation of $\mathrm{A} \beta$ in mitochondria could be the relationship for mitochondriamediated toxicity [4]. The Amyloid Precursor Protein (APP) was, indeed, found accumulated in the mitochondrial import channels and $\mathrm{A} \beta$ was found interacting with some mitochondrial proteins [5].

Here we dissect different points in which the mitochondrial functionality could be affected by $\mathrm{A} \beta$ presence, producing evidence from studies on $\mathrm{AD}$ human postmortem brains as well as cellular and AD animal models. Moreover, we analyze how these vulnerable points for $\mathrm{A} \beta$-mediated mitochondrial dysfunction may be distinctive and perhaps complementary therapeutic intervention targets for AD. 


\section{Mitochondria in Neuronal Cells}

High metabolic energy is required by human brain for its function. Since neurons have a limited glycolytic capacity this kind of cells is extremely dependent on mitochondrial energy production [6]. Neurons are cells with a particular morphology extending their axons and dendrites from millimeters up to a meter. Mitochondria are spread along the cells probably with a major presence in some regions of the neurons, as the synapses, that have the highest demand for ATP production and energy consumption. When a transmitter is released by a synapsis several ion channels are opened in the postsynaptic membrane to permit influx of ions. This pumping needs high energy consumption. Moreover, ATP produced by mitochondria is also consumed, together with all the normal requirements of a cell, for action potential to restore ion gradients and axonal transport. An imaging study established that a quiescent cortical neuron expends 4.7 billion ATP molecules per second [7]. A correct distribution of mitochondria into the neuronal regions in which a local demand for ATP or $\mathrm{Ca}^{2+}$ is necessary results to be important. Thus, trafficking of mitochondria is essential for neurons survival. Biochemical and imaging studies have demonstrated that mitochondrial translocation involves a motor/adaptor complex formed by microtubulebased motors proteins, as kinesin and dynein, together with two mitochondrion-specific proteins, milton and miro [8]. Moreover, mitochondrion together with energy metabolism discussed above plays in neurons a pivotal role in cell survival and death by regulating apoptotic pathways and contributing to different cellular functions including intracellular calcium homeostasis, maintaining the cellular redox potential, cell cycle regulation, and synaptic plasticity [9]. Mitochondrion has a role in establishing the polarity by reducing the $\mathrm{Ca}^{2+}$ concentration at the base of the presumptive axon, especially in neurons, thereby promoting polymerization of microtubules and the rapid neuronal growth and differentiation, accompanied by an increased amount of the mitochondria number per cell. This observation was achieved by studies in which treatment with chloramphenicol, an inhibitor of mitochondrial protein synthesis, prevents differentiation of the cells whereas oligomycin, an inhibitor of the mitochondrial ATP synthase, does not, thus suggesting that increased mitochondrial mass, but not ATP production, is required for neuronal differentiation [10]. Mitochondrial $\mathrm{Ca}^{2+}$ affects neurogenesis as suggested by results showing that an increase of mitochondrial fusion and intramitochondrial $\mathrm{Ca}^{2+}$ levels is observable when neuroblastoma cells are induced to stop division and begin differentiation in neuro-like cells [11]. During axons and dendrites differentiation, their growth and synaptic junction may be influenced by mitochondrial motility and functions. During the formation of axonal branches mitochondria respond to changes by modifying their entry into branches; the process does not require an active growth cone, suggesting the involvement of a different mechanism [12].

Furthermore, another intriguing mitochondrial role occurs during the self-renewal of neural stem cells. Studies on mouse embryonic stem (ES) cells suggest that the

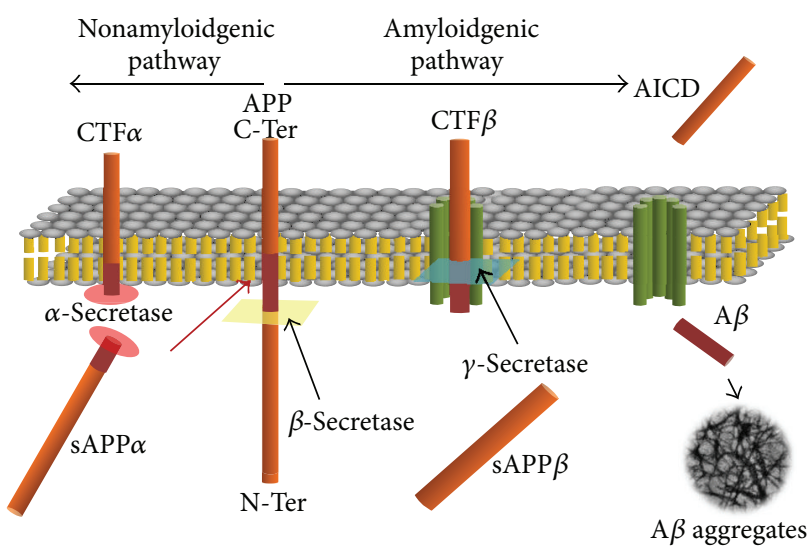

FIGURE 1: Nonamyloidgenic or amyloidgenic pathways are originated by different APP processing: the combined cleavage of $\alpha$ - and $\gamma$-secretase produces the sAPP $\alpha$ and CTF- $\alpha$ fragments preventing $\mathrm{A} \beta$ generation; in contrast, $\beta$-secretase cleaves in a different site of APP thus originating, together with $\gamma$-secretase complex, the sAPP $\beta$ and $\mathrm{A} \beta$ fragments and the intracellular AICD fragment. $\mathrm{A} \beta$ through a misfolding step forms fibrillar aggregates.

proliferative capacity is correlated with low mitochondrial oxygen consumption and high levels of glycolytic activity [13]. Human ES cells exhibit an anaerobic metabolic profile. When somatic cells are induced to revert to an ES cell-like phenotype their mitochondria follow the same fate changing their morphology, subcellular distribution, biogenesis, and ROS and ATP production [14].

On the basis of these observations it is easy to understand how several inherited diseases are caused by mutations in mitochondrial DNA, and cells as muscle cells and neurons, with high energy demands, are the most affected of these disorders. Furthermore, impaired mitochondrial activity causes the most common neurodegenerative disorders, such as Alzheimer's, Parkinson's and Huntington's diseases, stroke, and psychiatric disorders.

\section{APP Metabolism and $\mathbf{A} \beta$ Generation}

Alzheimer's disease is a devastating neurodegenerative disorder with a progressive cognitive impairment and dementia. $\mathrm{AD}$ pathogenesis is believed to be triggered by the $\mathrm{A} \beta$ accumulation, which is due to overproduction of $\mathrm{A} \beta$ and/or the failure of the clearance mechanisms. $\mathrm{A} \beta$ is generated by sequential cleavages of its larger precursor, a protein called amyloid precursor protein (APP). APP is an integral membrane protein with a single membrane spanning domain, a large extracellular glycosylated $\mathrm{N}$ terminus and a shorter cytoplasmic $\mathrm{C}$ terminus. APP is produced in several different isoforms and the most abundant form in brain (APP695) is produced mainly by neurons and diverges from the longest one because of the lacking of a kunitz-type protease inhibitor sequence in its ectodomain $[15,16]$. APP processing is divided into the nonamyloidogenic pathway and the amyloidogenic pathway (see Figure 1). The nonamyloidgenic processing is initiated by $\alpha$-secretases, cleaving within the $\mathrm{A} \beta$ domain 
and preventing the release of $\mathrm{A} \beta$ [17]. Alternatively, $\beta$ secretase (BACE1) cleavage initiates the amyloidogenic pathway and generates the soluble $\beta$-secreted APP $(\operatorname{sAPP} \beta)$ and the membrane bound fragment $\operatorname{CTF} \beta$. Both fragments are substrates for $\gamma$-secretase, a multisubunit protease complex comprising proteins as presenilin 1 or 2 (PS1, PS2) [18-21]. The further processing of CTF $\beta$ releases the amyloidogenic $\mathrm{A} \beta$ fragment $[22,23]$. Interestingly, $\gamma$-secretase seems to cleave the CTF $\beta$ exactly in the middle of the membrane domain [24], suggesting the hypothesis that the formation of different $A \beta$ species $\left(A \beta_{38}, A \beta_{40}\right.$, and $\left.A \beta_{42}\right)$ is dependent on the membrane properties. Each $\mathrm{A} \beta$ species have different lipophilic properties and different tendencies to form $A \beta$ oligomers and aggregates. Notably, the ratio $A \beta_{40} / A \beta_{42}$ is of clinical relevance in $\mathrm{AD}$ [25]. However, in $\mathrm{AD}$, the produced $\mathrm{A} \beta$ misfolds and self-aggregates into oligomers of various sizes and forms, up to produce diffuse amyloid neuritic plaques. $\mathrm{A} \beta$ oligomers and plaques are potent synaptotoxins, block proteasome function, inhibit mitochondrial activity, alter intracellular $\mathrm{Ca}^{2+}$ levels, and stimulate inflammatory processes.

\section{Mitochondrial A $\beta$}

$\mathrm{A} \beta$, as well as its extracellular canonical localization, has been found in different subcellular compartment including the endoplasmic reticulum (ER), the Golgi apparatus or the trans-Golgi network, the early, late, or recycling endosomes, and the lysosome, where probably is generated [26]. However, presence of $\mathrm{A} \beta$ has been also observed in mitochondria [27] and studies from different independent groups have clearly demonstrated that $\mathrm{A} \beta$ progressively accumulates within mitochondria of both human $\mathrm{AD}$ brain and $\mathrm{Tg}$ mouse models for $\mathrm{AD}$ [28]. Moreover, finding indicates that accumulation of $A \beta$ in mitochondria begins before the occurrence of the extracellular deposition as demonstrated by experiments in which its presence in $\mathrm{Tg} \mathrm{mA} \beta \mathrm{PP}$ mice arises as early as $4-5$ months and increases with aging [29]. The presence of $\mathrm{A} \beta$ in mitochondria was also evidenced by an interesting study in which APP modulates cell death through interaction with a newly identified mitochondrial membrane proapoptotic protein, called Appoptosin, involved in the heme synthesis [30]. These findings raise the question whether $\mathrm{A} \beta$ in mitochondria is in situ generated or imported. Several observations from different groups and experimental approaches demonstrated that $A \beta$ is not locally produced. This hypothesis is supported by the fact that the ability of $\gamma$ secretase to cleave APP associated with mitochondria is not known $[31,32]$. Thus, it is supposed that $A \beta$ is derived from its extracellular or intracellular pool and that a cellular trafficking is involved in the internalization of $\mathrm{A} \beta$ in mitochondria. Recent findings, using isolated rat mitochondria, have shown that a specific uptake mechanism for import of $A \beta$ in mitochondria involves the translocase of the outer membrane (TOM) complex [33]. This data was supported by the fact that extracellularly applied $A \beta$ is internalized in cells and colocalizes with mitochondrial markers and that is associated with the mitochondrial inner membrane after import. Other evidences come from experiments using confocal microscopy showing that the $\mathrm{A} \beta_{42}$ fragments colocalize with complex II of the respiratory chain, the outer cell membrane, the mitochondrial membrane, and the mitochondrial chaperon matrix protein Hsp60 [34, 35].

\section{Mitochondrial Dysfunction and Oxidative Stress Induced By $A \beta$}

Mitochondria have a pivotal role in cellular energy metabolism but are also involved in amino-acid, lipid, and steroid metabolism, modulation of cellular calcium levels, production of free radicals, and regulation of apoptosis, key features of neurodegeneration. Despite extensive research efforts to understand the pathophysiology of neurological diseases with respect to mitochondrial dysfunction, the exact mechanism is still not established. However, it seems clear that mitochondrial dysfunction plays a well-defined role in neurodegenerative diseases, making it a topic of high interest in neuroscience research today. An immediate consequence of mitochondrial dysfunction is the increase of reactive oxygen species (ROS) production that promotes oxidative damage to DNA, RNA, proteins, and lipids. Mitochondria are the primary cellular consumers of oxygen and contain numerous redox enzymes capable of transferring single electrons to oxygen, generating the superoxide $\left(\mathrm{O}_{2}^{-}\right)$molecules. Mitochondria also contain an extensive antioxidant defense system to detoxify the generated ROS. When mitochondria are damaged, the antioxidant defense decreases thus increasing ROS production that can further damage mitochondria, causing more free radicals generation and loss or depletion of antioxidant capacity. Under normal physiological conditions, ROS act as "redox messengers" regulating intracellular signalling, whereas imbalance of ROS induces irreversible damage to cellular components leading to cell death. Mitochondrial ROS can originate from multiple reactions in the TCA cycle and/or in the respiratory chain. Several in vitro studies suggested a link between elevated $\mathrm{A} \beta$ levels, mitochondrial dysfunction, and oxidative stress, all factors that contribute to AD pathogenesis. Moreover, we reported that $\mathrm{A} \beta$ is a key factor in free radical generation, oxidative damage, and mitochondrial dysfunction, activating a cascade of events leading to neurodegeneration in neuroblastoma LAN5 cells [36-38] and sea urchin model system [39].

Mitochondrial $\mathrm{A} \beta$ presence strongly influences mitochondrial respiratory function, ROS production rates, and alters mitochondrial membrane potential in different brain regions of $\mathrm{AD}$ mouse models. Moreover, a different mitochondrial distribution was evidenced. The elevated $\mathrm{A} \beta$ presence and the mitochondrial dysfunction were found in hippocampus and cortex, brain regions devoted to memory, whereas lower levels were found in striatum and amygdala. A striking association between mitochondrial impairment and cognitive dysfunction in the $\mathrm{A} \beta \mathrm{PP}$ and $\mathrm{A} \beta \mathrm{PP} / \mathrm{PS} 1$ mice was also found. This is the first demonstration of an association between mitochondrial $\mathrm{A} \beta$ levels, mitochondrial dysfunction, and cognitive impairment in $\mathrm{AD}$ transgenic mice [40]. 
Xie et al. for the first time showed how the structure and function of mitochondria changed in the living brain of transgenic animals developing amyloid deposits, by using intravital multiphoton imaging, with a range of fluorescent markers. The authors observed that severe impairments were limited in the brain regions close to the $A \beta$ plaques. In these regions a decreased number of mitochondria were found; some of them were dystrophic and fragmented and the survived ones showed a reduced membrane potential. Both neuronal soma and neuritis with oxidative stress show severe alterations in mitochondrial membrane potential. These results provide in vivo evidence that $\mathrm{A} \beta$ plaques can be focal sources of toxicity leading to severe structural and functional abnormalities in mitochondria [41]. Oxidative stress may activate signalling pathways that alter APP or Tau processing. For example, oxidative stress increases the expression of $\beta$-secretase through activation of c-Jun aminoterminal kinase and p38 mitogen-activated protein kinase (MAPK) [42] and increases aberrant Tau phosphorylation by activation of glycogen synthase kinase $3-\beta$ (GSK3- $\beta$ ) [43]. Oxidant-induced inactivation of specific molecules may also be important. Using a proteomic approach, the prolyl isomerase PIN1 was found to be particularly sensitive to oxidative damage, being highly downregulated and oxidized in hippocampus of $\mathrm{AD}$ patients [44]. The oxidative modification of PIN1 was related to the loss of isomerase activity that is retained critical for neurofibrillary tangle formation. Later studies have demonstrated that PIN1 catalyses protein conformational changes that affect both APP and Tau processing [45]. Knockout of PIN1 increases amyloidogenic APP processing and intracellular $A \beta$ levels in mice. PIN1-knockout mice also exhibit Tau hyperphosphorylation, motor and behavioural deficits, and neuronal degeneration [46].

Moreover, the cause of mitochondrial dysfunction could be the alteration of mitochondria-associated ER membrane (MAM) function. MAM is a dynamic subcompartment of ER with a lipid raft-like structure intimately involved in cholesterol and phospholipid metabolism, calcium homeostasis, mitochondrial function and dynamics, bioenergetics, and cell signaling [47-49]. MAM is physically, biochemically, and reversibly associated to mitochondria and this organellar contact site is a critical intracellular signaling platform that determines cellular life and death. During cellular stress situations, like an altered cellular redox state, the MAM alters its set of regulatory proteins and consequently alters MAM functions. Presenilins and $\gamma$-secretase are enriched in ER subcompartment and it has been hypothesized that genetic and biochemical alterations in these factors affecting MAM function should be relevant for increased APP processing and $\mathrm{AD}$ progression. Moreover, in agreement with this hypothesis both in model systems as PS-knockdown cells and in fibroblasts from patients having familial (FDA) or sporadic (SDA) forms of AD, MAM functionality, measured by the amount of cholesterol and phosphatidylserine production, is increased [50-52]. Similarly an increased expression of MAM-associated proteins is found in postmortem $\mathrm{AD}$ brains [53].

\section{A $\beta$ Affects Mitochondrial Bioenergetics}

The bioenergetics effect induced by endogenous $\mathrm{A} \beta$ on mitochondrion was investigated both in 7WD4 and 7PA2, two cell lines used as cellular model for AD [54]. Functional impairment of the respiratory chain was found distributed among the protein complexes especially in complex I and complex IV. Measurements of ATP concentration showed, in 7WD4 and 7PA2 cells, that its synthesis, by oxidative phosphorylation, was decreased by $\sim 25 \%$, and this loss was somewhat compensated by glycolysis (Warburg effect). Compensation proved to be more efficient in 7WD4 than in 7PA2 cells in agreement with the highest ROS production of the latter cell line. Moreover, the mitochondrial membrane potential was $40 \%$ and $60 \%$ lower in 7WD4 and 7PA2 cells, respectively, compared to Chinese hamster ovary $(\mathrm{CHO})$ controls. Moreover, in different AD models, the voltagedependent anion channel VDAC, a major component of the outer mitochondrial membrane that regulates ion fluxes and metabolites, is damaged as a result of oxidative stress [55]. The lipid composition of lipid rafts, key membrane microdomains that facilitate the transfer of substrates, and protein-protein and lipid-protein interactions is altered as a result of the abnormally low levels of n-3 long chain polyunsaturated fatty acids (mainly docosahexaenoic acid) that increase viscosity and augment energy consumption. Abnormal lipid raft composition may also modify the activity of the key enzymes that modulate the cleavage of the APP to form toxic $\mathrm{A} \beta$ [55]. Cholesterol and sphingolipids, that are rich in membrane microdomains, change their metabolism during normal brain aging and in the brains of $\mathrm{AD}$ patients resulting in accumulation of long chain ceramides and cholesterol [56]. Similarly, exposure of hippocampal neurons to $A \beta$ induces membrane oxidative stress that perturbs cholesterol metabolism and activates sphingomyelinases, resulting in increased ceramide production. In contrast, treatment of neurons with $\alpha$-tocopherol or an inhibitor of sphingomyelin synthesis prevents accumulation of ceramides and cholesterol and protects them against $A \beta$ induced death [56].

All these alterations converge in a severe bioenergetics mitochondria impairment of the $\mathrm{AD}$ cells, with the extent of mitochondrial dysfunction being correlated with the accumulation of $\mathrm{A} \beta$ and oligomers.

Mitochondria are the principal site for the ATP production oxidative phosphorylation (OXPHOS) system. The mitochondrial OXPHOS machinery, whose components are produced by mitochondrial genome, is composed of five multisubunit complexes (complexes I-V). Several studies have shown that direct exposure to $\mathrm{A} \beta$ significantly impairs functionality of the mitochondrial electron transport chain (ETC). The ETC is essential to ATP production and its constituent enzyme complexes are a major source of ROS generation, especially when one or more of the enzyme complexes is inhibited [57-59]. Moreover, age-related bioenergetics deficit was described in female of 3xTg-AD mice aged from 3 to 12 months [60]. A decreased activity of OXPHOS, pyruvate dehydrogenase (PDH), and cytochrome $c$ oxidase (COX) regulatory enzymes and increased oxidative stress and lipid peroxidation were found. Most of the effects 
on mitochondria appeared at the age of 9 months, whereas mitochondrial respiration was significantly decreased at 12 months of age. Importantly, mitochondrial bioenergetics deficit preexists at the development of $\mathrm{AD}$ pathology in 3xTgAD mice.

APP is known to be alternatively spliced to produce three major isoforms in the brain: APP695, APP751, and APP770. Both APP770 and APP751 contain the Kunitz protease inhibitory (KPI) domain, but the former contains also an extra OX-2 domain. APP695 on the other hand lacks both domains. In $\mathrm{AD}$, upregulation of the KPI-containing APP isoforms has been reported. Chua et al. found that the KPIcontaining APP751 significantly decreased the expression of three major mitochondrial metabolic enzymes such as citrate synthase, succinate dehydrogenase, and cytochrome $c$ oxidase (COX IV). This reduction lowers the NAD+/NADH ratio, COX IV activity, and mitochondrial membrane potential [61].

\section{Mitochondrial Biogenesis and AD}

During the life cycle, the biogenesis of new mitochondria plays an essential role in maintaining healthy mitochondria in eukaryotic cells. Mitochondrial biogenesis could also have the potentiality to quickly respond to changes due to mitochondrial damage or increased demand in response to environmental stimuli. Mitochondrial biogenesis is regulated by the PGC-1 $\alpha$-NRFTFAM pathway. Expression levels of PGC-1 $\alpha$, NRF 1, NRF 2, and TFAM were significantly decreased in both AD hippocampal tissue and APPswe M17 cells, suggesting that mitochondrial biogenesis was affected during neurodegeneration. Moreover, it has been demonstrated that impaired mitochondrial biogenesis contributes to mitochondrial dysfunction in $\mathrm{AD}$ and its enhancing may represent a potential pharmacologic approach for the treatment of $\mathrm{AD}[62]$.

\section{Abnormal Mitochondrial Dynamics in AD}

Despite traditional knowledge, mitochondria are now considered highly dynamic organelles that move throughout a cell and regularly fuse and divide. Increasing evidence suggests that abnormal mitochondrial dynamics, such as increased fission and decreased fusion, are early and key factors that have been found in neurodegenerative diseases, such as AD. These processes observed in axons and dendrites, as in all cells, allow the exchange of materials between mitochondria [63]. Even brief contact can involve fusion and extensive exchange of proteins in each compartment of the mitochondrion, as it has been shown in nonneuronal cells [64]. In addition, these abnormal mitochondrial dynamics have been associated with unusual changes in mitochondria structure. Abnormal mitochondrial fission and fusion were reported in $\mathrm{AD}$ [65]. In this study, the authors aimed to determine whether APP and A $\beta$ cause mitochondrial and neuronal dysfunction through modulation of mitochondrial dynamics [65]. Further, both confocal and electron microscopy analyses demonstrated that APP overexpression causes mitochondrial fragmentation in neurons [66]. Since the balance of mitochondrial fission and fusion tightly controls mitochondrial morphology, it was hypothesized that APP-induced mitochondrial fragmentation was caused by enhanced fission and reduced fusion [67]. Recent studies show that the fusion dynamin-related protein 1 (Drp1), also known as dynamin-like protein 1 (DLP1), a protein that maintains and remodels mammalian mitochondria, interacts with $\mathrm{A} \beta$ and phosphorylates Tau, leading to excessive mitochondrial fragmentation, impaired axonal transport of mitochondria, and lastly neuronal damage and cognitive decline [68]. However, in agreement with the idea that mitochondria dynamics are altered in $\mathrm{AD}$ neurons, significant changes in the expression of proteins involved in mitochondrial fission and fusion were reported. Reduced expression of all the fusion proteins (i.e., OPA1, Mfn1, and Mfn2) and increased expression of fission protein Fis1 were described [69-71].

\section{A $\beta$ Interacts and Interferes with Mitochondrial Proteins}

Structurally and functionally intact mitochondria are crucial for healthy cells. A mitochondrion contains outer and inner membranes composed of phospholipid bilayers and proteins having different properties and their integrity is essential for its good functionality. In cell death mechanisms, as apoptosis and necrosis, an increase of mitochondrial membrane permeability is one of the key events. Mitochondria isolated from a variety of sources can show an abrupt increase in the permeability of the inner mitochondrial membrane to solutes with a molecular mass of less than $1,500 \mathrm{Da}$, which results in the loss of mitochondrial membrane potential $(\Delta \Psi \mathrm{m})$, mitochondrial swelling, and rupture of the outer mitochondrial membrane. This process is better known as the mitochondrial membrane permeability transition (MPT) [72]. The MPT can be induced under various conditions, such as exposure of mitochondria to $\mathrm{Ca}^{2+}$ together with inorganic phosphate. Although the molecular mechanisms of the MPT are largely unknown, the most widely accepted model is that it occurs after the opening of a channel complex that has been termed the permeability transition pore (PTP), which is thought to consist of the voltage-dependent anion channel (VDAC: outer membrane channel), the adenine nucleotide translocator (ANT: inner membrane channel), cyclophilin D (CypD), and possibly other molecule(s). CypD, a peptidylprolyl isomerase $\mathrm{F}$, resides in the mitochondrial matrix but becomes associated with the inner mitochondrial membrane during the MPT and it plays a central role in opening the mitochondrial membrane permeability transition pore (mPTP). Recent studies provide evidence that CypD binds to $\mathrm{A} \beta$ and forms a complex with $\mathrm{A} \beta$ in cortical mitochondria of $\mathrm{AD}$ patients and $\mathrm{Tg} \mathrm{A} \beta \mathrm{PP}$ mice [73]. The interaction of $\mathrm{A} \beta$ with CypD provokes mitochondrial and neuronal perturbation [74]. This interaction causes the formation of mPTP, resulting in decreased mitochondrial membrane potential, compromised mitochondrial respiration function, increased oxidative stress, release of cytochrome $c$, and impaired axonal mitochondrial transport. It has been suggested that mPTP 
could be a possible therapeutic target. The design of small molecules able to interfere with $\mathrm{A} \beta$-CypD complex could, indeed, decrease $\mathrm{A} \beta$ neurotoxicity effects [74].

The involvement of mitochondria in the pathogenic pathway of $\mathrm{A} \beta$ was also confirmed by specific binding of $\mathrm{A} \beta$ and $\mathrm{A} \beta \mathrm{PP}$ to mitochondrial proteins, which causes energy impairment and cell physiology defects. Firstly, A $\beta$ specifically binds to the mitochondrial $\mathrm{A} \beta$-binding alcohol dehydrogenase (ABAD), an intracellular enzyme present in the mitochondrial matrix [75]. In presence of $A \beta, A B A D$ increases cell stress, DNA fragmentation, and ROS generation induced by $\mathrm{A} \beta$. Moreover, the expression levels of $\mathrm{ABAD}$ are related to mitochondrial $A \beta$ levels being $A B A D$ expression levels significantly higher in $\mathrm{AD}$-affected brain regions, as hippocampus, than in healthy brain [75]. Recent experiments indicate that the 94-114 ABAD residues interact with $A \beta$ and inhibition of the ABAD-A $\beta$ interaction significantly reduces mitochondrial $A \beta$ accumulation and protects against aberrant mitochondrial and neuronal function, improving spatial learning/memory in Tg AD mice [76-78]. Proteomics studies on Tg mAPP/ABAD mice showed that in brain the $\mathrm{ABAD}-\mathrm{A} \beta$ interaction also affects the expression of proteins such as Ep-1 (endophilin-1), a cytoplasmic SH3 domaincontaining protein, located in presynaptic nerve termini [79] and Prdx-2 (peroxiredoxin-2), an antioxidant protein [80], both of which were also found to be overexpressed in human $\mathrm{AD}$ brains $[79,80]$. Even if the link between these two proteins and mitochondrial dysfunction remains unclear some evidences indicate that increased levels of Ep1 cause the activation of JNK (c-Jun-N-terminal kinase) $[79,81]$. JNK is a stress kinase that has been linked to $\mathrm{A} \beta$ production and neurons death [82]. Thus, all these data support the significance of $\mathrm{ABAD}$ to $\mathrm{A} \beta$ induced neuronal stress. Several enzymes, such as presequence protease (PreP), a metalloprotease containing an inverted zinc binding motif, were identified to degrade $A \beta[83,84]$. Intramitochondrial localization studies demonstrated that PreP is localized within the mitochondrial matrix. PreP activity is severely reduced in samples of mitochondrial matrix isolated from the temporal lobe of $\mathrm{AD}$ patients, compared to age-matched controls [85]. Moreover, exposure of purified hPreP to an oxidizing agent, hydrogen peroxide, results in decreased peptidolytic activity [86]. During oxidative phosphorylation, the electron transporters release energy that drives the production of ATP. A $\beta$ may inhibit mitochondrial respiration, by interacting with the subunit $\alpha$ of ATP synthase causing ATP depletion [87]. Another study reports that A $\beta$ decreases cytochrome $c$ oxidase activity, but the specific mechanism is still unclear [88]. In contrast, an increase in the activity of the cytochrome $c$ reductase (complex III) has been reported [89]. Interestingly, complex III appears to be one of the sites of superoxide radical production. Bobba et al. found that $\mathrm{A} \beta$ caused a selective defect in complex I activity, associated with an increase of intracellular ROS (5-fold) and an impairment of complex IV, likely due to membrane lipid peroxidation. In addition, a $130 \%$ increase of the GSSG/GSH ratio was measured in $\mathrm{AD}$ brains with respect to age-matched controls [90].

\section{Therapeutic Strategies against $\mathbf{A} \beta$ Induced Mitochondrial Toxicity}

The free radical and oxidative stress theory of aging suggests that oxidative damage is a major player in neuronal degeneration and oxidative stress has a well-established pathophysiological feature in $\mathrm{AD}$ [91]. However, up to now use of antioxidants in prevention or therapy gives controversial results. One possible explanation is related to the low permeability of the blood brain barrier (BBB) to most of the currently used antioxidants. To overcome these potential difficulties, researchers have formulated new delivery systems, such as those based on nanoparticles, which might represent a successful strategy for drug delivery into CNS. Moreover, on the basis of the consideration that mitochondria are the major source of ROS and are particularly vulnerable to oxidative stress, one would predict that a more efficient therapy could consider use of antioxidants alleviating mitochondrial dysfunction. This prompted researchers to develop antioxidant therapy directed to mitochondrion, through the development of specifically designed mitochondria-targeted antioxidants [92,93]. This might be a strategy to overcome the apparent clinical inefficiency of antioxidants that do not target oxidative stress in this organelle [94]. The SzetoSchiller (SS) peptides, a family of small mitochondriatargeted antioxidant molecules, were developed as a potential treatment for $\mathrm{AD}$ [95]. These SS peptides display mitochondrial accumulation having a sequence motif that allows them to target mitochondria. They scavenge $\mathrm{H}_{2} \mathrm{O}_{2}$ and inhibit lipid peroxidation. Their antioxidant action can be attributed to the tyrosine, or dimethyltyrosine (Dmt), that plays a role in scavenging mitochondrial ROS. SS31, in particular, is capable of entering mitochondria and of concentrating in the inner mitochondrial membrane, protecting mitochondria against mPTP formation, swelling, and cytochrome $c$ release. Using SS31 in different AD models as N2a neuroblastoma cells treated with $\mathrm{A} \beta_{25-35}$, primary neurons from $\mathrm{Tg} 2576$ mice and aged Tg2576 mice, a range of effects on mitochondria were observed [96, 97]. Increased expression of mitochondrial fission genes and decreased expression of fusion genes were found together with increased number of mitochondria, indicating that mitochondria fragmentation occurred. On the basis of these results, the Antipodean Pharmaceuticals Inc. patented MitoQ, a mitochondria-targeted antioxidant. This drug is now undergoing phase II clinical trials for the potential treatment of several diseases in which mitochondrial oxidative damage is implicated, including neurodegenerative diseases [98]. MitoQ was designed to accumulate extensively within mitochondria in vivo in order to increase the local antioxidant capacity against oxidative damage. The active drug is the ubiquinone, which is identical to the antioxidant component of the respiratory chain constituent coenzyme Q10 (CoQ10). An aliphatic 10-carbon chain, to the lipophilic cation triphenylphosphonium, that drives its selective uptake into mitochondria in a membrane potentialdependent manner, covalently links this component. Once internalized by mitochondria, it adsorbs in the phospholipid bilayers, where it is readily reduced to the active ubiquinol form MitoQH2, which exerts its antioxidant properties [99]. 

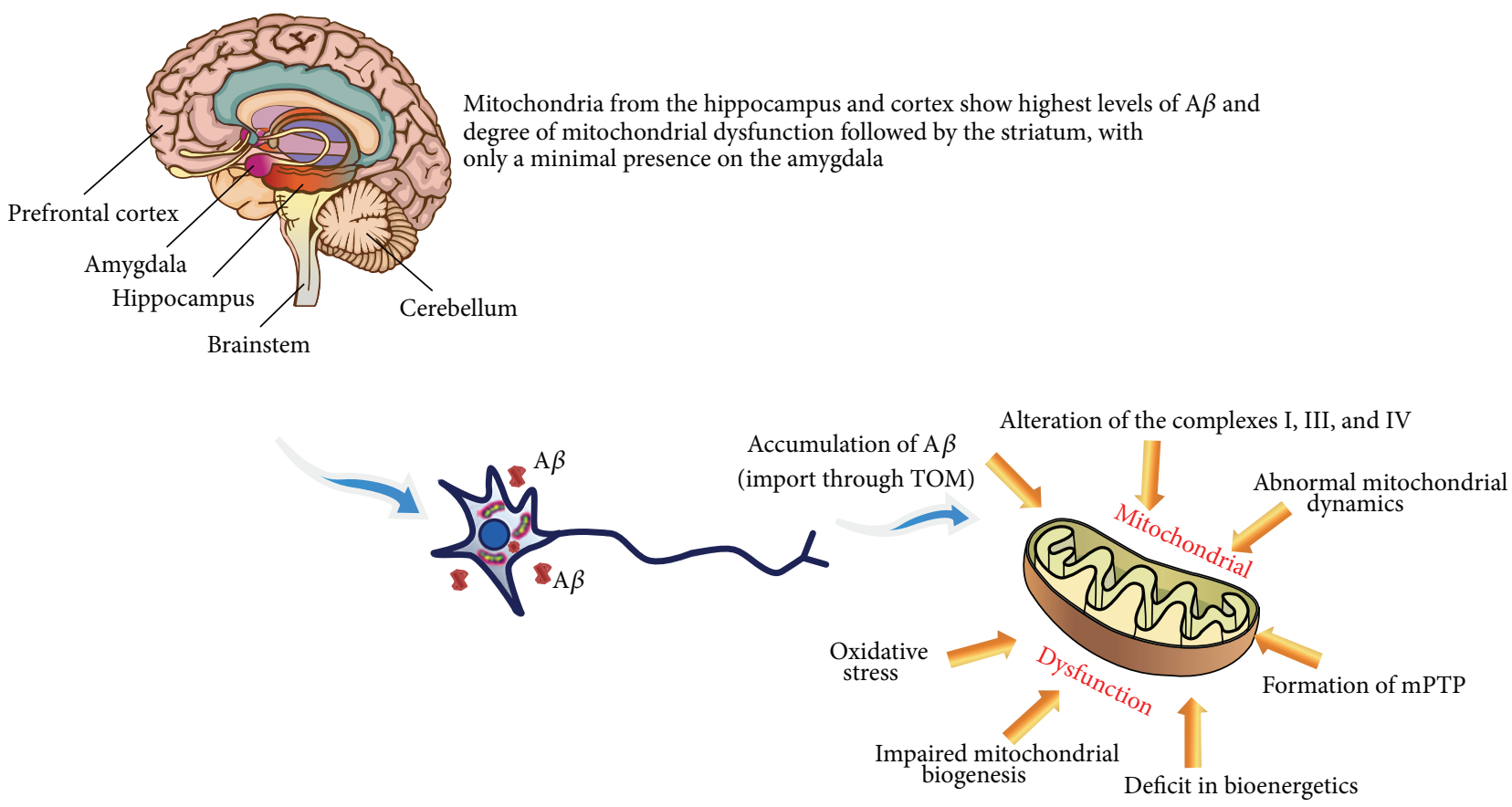

FIGURE 2: Mitochondrial dysfunction induced by $\mathrm{A} \beta$. In $\mathrm{AD}$ brain some areas are more sensitive to mitochondrial dysfunction. In the neurons $\mathrm{A} \beta$ induces mitochondrial dysfunction by using different mechanisms. $\mathrm{A} \beta$ is taken up by mitochondria via the TOM complex and imported in the inner membrane; $\mathrm{A} \beta$ alters the enzyme activity of the respiratory chain complexes I, II, and IV; $A \beta$ affects mitochondrial dynamics by impaired balance of fission and fusion; $\mathrm{A} \beta$ causes formation of $\mathrm{mPTP}$ via interaction with $\mathrm{CypD}$; $\beta$ induces decreased mitochondrial respiration; $\mathrm{A} \beta$ affects new mitochondrial biogenesis; $\mathrm{A} \beta$ increases ROS generation.

Since it enters into mitochondria several hundred-fold more than natural antioxidants, it rapidly neutralizes free radicals at their source, before they reach their targets, thus showing an improved therapeutic potential [100]. For all these proprieties, MitoQ is a promising antioxidant candidate for AD treatment [94]. Recently, using cytoplasmic hybrid (cybrid) neurons from $\mathrm{AD}$ and age-matched non-AD human subjects, it was demonstrated that treatment with the antioxidant probucol protects against $\mathrm{AD}$ mitochondria-induced extracellular signal-regulated kinase (ERK) activation and mitochondrial fission-fusion imbalances. In fact, inhibition of ERK activation not only attenuates aberrant mitochondrial morphology and function but also reestablishes the mitochondrial fission and fusion balance, as confirmed by changes in expression and distribution of DLP1 and Mfn2 [101].

Among antioxidant molecules used in prevention and treatment of $\mathrm{AD}$, a relevant role is played by natural antioxidants [102]. The curry spice curcumin shows antioxidant [103], anti-inflammatory [104], and amyloid-disaggregating properties [105], effects that have been largely studied both in vitro and in vivo models. A pilot clinical trial to develop procedures for testing the effectiveness of curcumin on slowing AD progression was carried out [106]. Thirty-four human subjects with $\mathrm{AD}$ received daily placebo or two different doses of curcumin for 6 months. At different times of the study, cognitive tests were performed, and blood samples were analyzed for levels of isoprostane, amyloid beta protein, metals, and cholesterol. There was no cognitive decline in the placebo group, and no improvement was observed with curcumin. Moreover, curcumin presented low bioavailability and photodegradation. With such issues in mind, Marrache and Dhar formulated targeted curcuminloaded NPs (mitochondria-targeted polymeric nanoparticle system) to provide photostability and enhance mitochondrial uptake. An in vitro cytotoxicity assay, using $\mathrm{A} \beta$ treated human neuroblastoma IMR-32 cells, demonstrated enhanced neuroprotection with the targeted curcumin NPs compared with the no-targeted curcumin NPs or free curcumin against $\mathrm{A} \beta$, which accounts for the targeted delivery of curcumin into the mitochondria of cells [107]. Ferulic acid (FA) is another natural antioxidant having a neuroprotective effect against oxidative stress and cell death induced by $\mathrm{A} \beta_{42}$ oligomers [36]. FA was also successfully conjugated with solid lipid nanoparticles to improve its delivery and enhance its potential antioxidant therapeutic effect [36]. Moreover, other data suggest that natural plants such as a standardized Ginkgo biloba extract or the green tea component epigallocatechin3-gallate may be promising treatment strategies. Of note, in addition to their antioxidative properties, these compounds stabilize mitochondrial functions such as the mitochondrial membrane potential, ATP levels, and mitochondrial respiratory complexes $[108,109]$. As discussed above, the interaction of $\mathrm{A} \beta$ with $\mathrm{CypD}$ provokes mitochondrial perturbation and formation of mPTP events leading to neuronal degeneration. Thus, inhibition of mPTP formation by blocking CypD is a rational target for potential therapeutic $\mathrm{AD}$ strategies. 


\section{Conclusions}

Mitochondrial dysfunction is an early feature of Alzheimer's disease. Extracellular or intracellular $\mathrm{A} \beta$ is imported into the mitochondria through the TOM machinery. The progressive accumulation of mitochondrial $\mathrm{A} \beta$ is associated with aberrant mitochondrial functions leading to neuronal damage and cognitive decline. The mitotoxicity induced by $\mathrm{A} \beta$ is still not clear but includes numerous mechanisms. $\mathrm{A} \beta$ induced mitochondrial dysfunction contributes to energy metabolism impairment, defects in key respiratory enzyme activity/function, accumulation/generation of mitochondrial ROS, formation of mPTP, altered mitochondrial biogenesis, and dynamics. Binding of $\mathrm{A} \beta$ to mitochondrial proteins (CypD and $\mathrm{ABAD}$ ) amplifies $\mathrm{A} \beta$ induced effects on mitochondria and neuron functions (Figure 2). From these insights, it is easy to deduce how mitochondrion offers multiple points to develop strategies against mitochondrial dysfunction. Thus, not only antioxidant targeted therapeutic strategies but also specific mitochondrial targeted therapeutic strategies should be explored for neuroprotection against $A \beta$ toxicity.

\section{Conflict of Interests}

The authors declare that there is no conflict of interests regarding the publication of this paper.

\section{Authors' Contribution}

Pasquale Picone and Domenico Nuzzo contributed equally to this paper.

\section{Acknowledgments}

The authors deeply thank Dr. Daniela Giacomazza for the critical revision of the paper. This work was supported by the Italian Ministry of Economy and Finance with the "PNRCNR Aging Program 2012-2014" Project.

\section{References}

[1] D. M. Walsh and D. J. Selkoe, "A $\beta$ oligomers: a decade of discovery," Journal of Neurochemistry, vol. 101, no. 5, pp. 11721184, 2007.

[2] P. I. Moreira, C. Carvalho, X. Zhu, M. A. Smith, and G. Perry, "Mitochondrial dysfunction is a trigger of Alzheimer's disease pathophysiology," Biochimica et Biophysica Acta, vol. 1802, no. 1, pp. 2-10, 2010.

[3] R. H. Swerdlow, J. M. Burns, and S. M. Khan, "The Alzheimer's disease mitochondrial cascade hypothesis," Journal of Alzheimer's Disease, vol. 20, no. 2, pp. S265-S279, 2010.

[4] J. X. Chen and S. S. Yan, "Role of mitochondrial amyloid-beta in Alzheimers disease," Journal of Alzheimer's Disease, vol. 20, no. 2, pp. S569-S578, 2010.

[5] L. Tillement, L. Lecanu, and V. Papadopoulos, "Alzheimer's disease: effects of $\beta$-amyloid on mitochondria," Mitochondrion, vol. 11, no. 1, pp. 13-21, 2011.
[6] P. I. Moreira, A. I. Duarte, M. S. Santos, A. C. Rego, and C. R. Oliveira, "An integrative view of the role of oxidative stress, mitochondria and insulin in Alzheimer's disease," Journal of Alzheimer's Disease, vol. 16, no. 4, pp. 741-761, 2009.

[7] X. H. Zhu, H. Qiao, F. Du et al., "Quantitative imaging of energy expenditure in human brain," Neuroimage, vol. 60, no. 4, pp. 2107-2117, 2012.

[8] T. L. Schwarz, "Mitochondrial trafficking in neurons," Cold Spring Harbor Perspectives in Biology, vol. 5, no. 6, 2013.

[9] M. P. Mattson, M. Gleichmann, and A. Cheng, "Mitochondria in neuroplasticity and neurological disorders," Neuron, vol. 60, no. 5, pp. 748-766, 2008.

[10] J. L. Vayssiere, L. Cordeau-Lossouarn, J. C. Larcher, M. Basseville, F. Gros, and B. Croizat, "Participation of the mitochondrial genome in the differentiation of neuroblastoma cells," In Vitro Cellular and Developmental Biology, vol. 28, no. 11-12, pp. 763-772, 1992.

[11] V. Voccoli and L. Colombaioni, "Mitochondrial remodeling in differentiating neuroblasts," Brain Research, vol. 1252, pp. 15-29, 2009.

[12] G. Ruthel and P. J. Hollenbeck, "Response of mitochondrial traffic to axon determination and differential branch growth," Journal of Neuroscience, vol. 23, no. 24, pp. 8618-8624, 2003.

[13] H. Kondoh, M. E. Lleonart, D. Bernard, and J. Gil, "Protection from oxidative stress by enhanced glycolysis; a possible mechanism of cellular immortalization," Histology and Histopathology, vol. 22, no. 1-3, pp. 85-90, 2007.

[14] Y. Wang, N. Mah, A. Prigione, K. Wolfrum, M. A. AndradeNavarro, and J. Adjaye, "A transcriptional roadmap to the induction of pluripotency in somatic cells," Stem Cell Reviews and Reports, vol. 6, no. 2, pp. 282-296, 2010.

[15] J. Hardy, "Amyloid, the presenilins and Alzheimer's disease," Trends in Neurosciences, vol. 20, no. 4, pp. 154-159, 1997.

[16] M. P. Mattson, "Cellular action sofbeta-amyloid precursor protein and its soluble and fibrillogenic derivative," Physiological Reviews, vol. 77, pp. 1081-1132, 1997.

[17] S. Lammich, E. Kojro, R. Postina et al., "Constitutive and regulated $\alpha$-secretase cleavage of Alzheimer's amyloid precursor protein by a disintegrin metalloprotease," Proceedings of the National Academy of Sciences of the United States of America, vol. 96, no. 7, pp. 3922-3927, 1999.

[18] M. O. Grimm, I. Tomic, and T. Hartmann, "Potential external source of A $\beta$ in biological samples," Nature Cell Biology, vol. 4, pp. E164-E165, 2002.

[19] S. S. Sisodia and P. H. St George-Hyslop, " $\gamma$-secretase, Notch, $\mathrm{A} \beta$ and Alzheimer's disease: where do the presenilins fit in?" Nature Reviews Neuroscience, vol. 3, no. 4, pp. 281-290, 2002.

[20] B. de Strooper, "Aph-1, Pen-2, and Nicastrin with Presenilin generate an active $\gamma$-Secretase complex," Neuron, vol. 38, no. 1 , pp. 9-12, 2003.

[21] H. Steiner, R. Fluhrer, and C. Haass, "Intramembrane proteolysis by $\gamma$-secretase," The Journal of Biological Chemistry, vol. 283, no. 44, pp. 29627-29631, 2008.

[22] C. Haass, M. G. Schlossmacher, A. Y. Hung et al., "Amyloid $\beta$-peptide is produced by cultured cells during normal metabolism," Nature, vol. 359, no. 6393, pp. 322-325, 1992.

[23] C. Haass, A. Y. Hung, M. G. Schlossmacher, D. B. Teplow, and D. J. Selkoe, " $\beta$-Amyloid peptide and a $3-\mathrm{kDa}$ fragment are derived by distinct cellular mechanisms," The Journal of Biological Chemistry, vol. 268, no. 5, pp. 3021-3024, 1993. 
[24] B. Grziwa, M. O. W. Grimm, C. L. Masters, K. Beyreuther, T. Hartmann, and S. F. Lichtenthaler, "The transmembrane domain of the amyloid precursor protein in microsomal membranes is on both sides shorter than predicted," Journal of Biological Chemistry, vol. 278, no. 9, pp. 6803-6808, 2003.

[25] M. Duering, M. O. W. Grimm, H. S. Grimm, J. Schröder, and T. Hartmann, "Mean age of onset in familial Alzheimer's disease is determined by amyloid beta 42," Neurobiology of Aging, vol. 26, no. 6, pp. 785-788, 2005.

[26] R. W. Choy, Z. Cheng, and R. Schekman, "Amyloid precursor protein (APP) traffics from the cell surface via endosomes for amyloid $\beta(\mathrm{A} \beta)$ production in the trans-Golgi network," Proceedings of the National Academy of Sciences of the United States of America, vol. 109, no. 30, pp. E2077-E2082, 2012.

[27] M. Y. Cha, S. H. Han, S. M. Son et al., "Mitochondria-specific accumulation of amyloid $\beta$ induces mitochondrial dysfunction leading to apoptotic cell death," PLoS ONE, vol. 7, no. 4, Article ID e34929, 2012.

[28] J. X. Chen and S. D. Yan, "Amyloid- $\beta$-induced mitochondrial dysfunction," Journal of Alzheimer's Disease, vol. 12, no. 2, pp. 177-184, 2007.

[29] C. Caspersen, N. Wang, J. Yao et al., "Mitochondrial A $\beta$ : a potential focal point for neuronal metabolic dysfunction in Alzheimer's disease," The FASEB Journal, vol. 19, no. 14, pp. 2040-2041, 2005.

[30] H. Zhang, Y. Zhang, Y. Chen et al., "Appoptosin is a novel proapoptotic protein and mediates cell death in neurodegeneration," Journal of Neuroscience, vol. 32, no. 44, pp. 15565-15576, 2012.

[31] H. K. Anandatheerthavarada, G. Biswas, M. Robin, and N. G. Avadhani, "Mitochondrial targeting and a novel transmembrane arrest of Alzheimer's amyloid precursor protein impairs mitochondrial function in neuronal cells," Journal of Cell Biology, vol. 161, no. 1, pp. 41-54, 2003.

[32] L. Devi, B. M. Prabhu, D. F. Galati, N. G. Avadhani, and H. K. Anandatheerthavarada, "Accumulation of amyloid precursor protein in the mitochondrial import channels of human Alzheimer's disease brain is associated with mitochondrial dysfunction," Journal of Neuroscience, vol. 26, no. 35, pp. 90579068, 2006.

[33] C. A. Hansson Petersen, N. Alikhani, H. Behbahani et al., "The amyloid $\beta$-peptide is imported into mitochondria via the TOM import machinery and localized to mitochondrial cristae," Proceedings of the National Academy of Sciences of the United States of America, vol. 105, no. 35, pp. 13145-13150, 2008.

[34] L. Tillement, L. Lecanu, W. Yao, J. Greeson, and V. Papadopoulos, "The spirostenol (22R, 25R)-20 $\alpha$-spirost-5-en-3 $\beta$-yl hexanoate blocks mitochondrial uptake of $\mathrm{A} \beta$ in neuronal cells and prevents $A \beta$-induced impairment of mitochondrial function," Steroids, vol. 71, no. 8, pp. 725-735, 2006.

[35] K. C. Walls, P. Coskun, J. L. Gallegos-Perez et al., "Swedish Alzheimer mutation induces mitochondrial dysfunction mediated by HSP60 mislocalization of amyloid precursor protein (APP) and $\beta$-amyloid," The Journal of Biological Chemistry, vol. 287, no. 36, pp. 30317-30327, 2012.

[36] P. Picone, M. L. Bondi, G. Montana et al., "Ferulic acid inhibits oxidative stress and cell death induced by Ab oligomers: improved delivery by solid lipid nanoparticles," Free Radical Research, vol. 43, no. 11, pp. 1133-1145, 2009.

[37] P. Picone, R. Carrotta, G. Montana, M. R. Nobile, P. L. San Biagio, and M. Di Carlo, "A $\beta$ oligomers and fibrillar aggregates induce different apoptotic pathways in LAN5 neuroblastoma cell cultures," Biophysical Journal, vol. 96, no. 10, pp. 4200-4211, 2009.

[38] M. Di Carlo, D. Giacomazza, P. Picone, D. Nuzzo, and P. L. San Biagio, "Are oxidative stress and mitochondrial dysfunction the key players in the neurodegenerative diseases?" Free Radical Research, vol. 46, no. 11, pp. 1327-1338, 2012.

[39] P. Picone, D. Nuzzo, and M. Di Carlo, "Ferulic acid: a natural antioxidant against oxidative stress induced by oligomeric Abeta on sea urchin embryo," Biological Bulletin, vol. 224, no. 1, pp. 18-28, 2013.

[40] N. Dragicevic, M. Mamcarz, Y. Zhu et al., "Mitochondrial amyloid- $\beta$ levels are associated with the extent of mitochondrial dysfunction in different brain regions and the degree of cognitive impairment in Alzheimer's transgenic mice," Journal of Alzheimer's Disease, vol. 20, no. 2, pp. S535-S550, 2010.

[41] H. Xie, J. Guan, L. A. Borrelli, J. Xu, A. Serrano-Pozo, and B. J. Bacskai, "Mitochondrial alterations near amyloid plaques in an alzheimer's disease mouse model," The Journal of Neuroscience, vol. 33, no. 43, pp. 17042-17051, 2013.

[42] E. Tamagno, M. Parola, P. Bardini et al., " $\beta$-site APP cleaving enzyme up-regulation induced by 4-hydroxynonenal is mediated by stress-activated protein kinases pathways," Journal of Neurochemistry, vol. 92, no. 3, pp. 628-636, 2005.

[43] M. A. Lovell, S. Xiong, C. Xie, P. Davies, and W. R. Markesbery, "Induction of hyperphosphorylated tau in primary rat cortical neuron cultures mediated by oxidative stress and glycogen synthase kinase-3," Journal of Alzheimer's Disease, vol. 6, no. 6, pp. 659-671, 2004.

[44] R. Sultana, D. Boyd-Kimball, H. F. Poon et al., "Oxidative modification and down-regulation of Pin1 in Alzheimer's disease hippocampus: a redox proteomics analysis," Neurobiology of Aging, vol. 27, no. 7, pp. 918-925, 2006.

[45] L. Pastorino, A. Sun, P. J. Lu et al., “The prolyl isomerase Pin1 regulates amyloid precursor protein processing and amyloid- $\beta$ production," Nature, vol. 440, no. 7083, pp. 528-534, 2006.

[46] Y. Liou, A. Sun, A. Ryo et al., "Role of the prolyl isomerase Pinl in protecting against age-dependent neurodegeneration," Nature, vol. 424, no. 6948, pp. 556-561, 2003.

[47] R. Rizzuto, P. Pinton, W. Carrington et al., "Close contacts with the endoplasmic reticulum as determinants of mitochondrial $\mathrm{Ca}^{+}{ }^{+}$responses," Science, vol. 280, no. 5370, pp. 1763-1766, 1998.

[48] A. Raturi and T. Simmen, "Where the endoplasmic reticulum and the mitochondrion tie the knot: the mitochondriaassociated membrane (MAM)," Biochimica et Biophysica ActaMolecular Cell Research, vol. 1833, no. 1, pp. 213-224, 2013.

[49] A. R. van Vliet, T. Verfaillie, and P. Agostinis, "New functions of mitochondria associated membranes in cellular signaling," Biochimica et Biophysica Acta-Molecular Cell Research, vol. 1843, no. 10, pp. 2253-2262, 2014.

[50] E. Area-Gomez, M. Del Carmen Lara Castillo, M. D. Tambini et al., "Upregulated function of mitochondria-associated ER membranes in Alzheimer disease," EMBO Journal, vol. 31, no. 21, pp. 4106-4123, 2012.

[51] E. A. Schon and E. Area-Gomez, "Is Alzheimer's disease a disorder of mitochondria-associated membranes?" Journal of Alzheimer's Disease, vol. 20, no. 2, pp. S281-S292, 2010.

[52] E. A. Schon and E. Area-Gomez, "Mitochondria-associated ER membranes in Alzheimer disease," Molecular and Cellular Neuroscience, vol. 55, pp. 26-36, 2013.

[53] L. Hedskog, C. M. Pinho, R. Filadi et al., "Modulation of the endoplasmic reticulum-mitochondria interface in Alzheimer's 
disease and related models," Proceedings of the National Academy of Sciences of the United States of America, vol. 110, no. 19, pp. 7916-7921, 2013.

[54] N. Krako, M. C. Magnifico, M. Arese et al., "Characterization of mitochondrial dysfunction in the 7PA2 cell model of Alzheimer's disease," Journal of Alzheimer's Disease, vol. 37, no. 4, pp. 747-758, 2013.

[55] I. Ferrer, "Altered mitochondria, energy metabolism, voltagedependent anion channel, and lipid rafts converge to exhaust neurons in Alzheimer's disease," Journal of Bioenergetics and Biomembranes, vol. 41, no. 5, pp. 425-431, 2009.

[56] R. G. Cutler, J. Kelly, K. Storie et al., "Involvement of oxidative stress-induced abnormalities in ceramide and cholesterol metabolism in brain aging and Alzheimer's disease," Proceedings of the National Academy of Sciences of the United States of America, vol. 101, no. 7, pp. 2070-2075, 2004.

[57] P. J. Crouch, S. M. E. Harding, A. R. White, J. Camakaris, A. I. Bushd, and C. L. Masters, "Mechanisms of Ab mediated neurodegeneration in Alzheimer's disease," International Journal of Biochemistry \& Cell Biology, vol. 40, pp. 181-198, 2008.

[58] V. Chauhan and A. Chauhan, "Oxidative stress in Alzheimer's disease," Pathophysiology, vol. 13, no. 3, pp. 195-208, 2006.

[59] H. Fukui and C. T. Moraes, "The mitochondrial impairment, oxidative stress and neurodegeneration connection: reality or just an attractive hypothesis?" Trends in Neurosciences, vol. 31, no. 5, pp. 251-256, 2008.

[60] J. Yao, R. W. Irwin, L. Zhao, J. Nilsen, R. T. Hamilton, and R. D. Brinton, "Mitochondrial bioenergetic deficit precedes Alzheimer's pathology in female mouse model of Alzheimer's disease," Proceedings of the National Academy of Sciences of the United States of America, vol. 106, no. 34, pp. 14670-14675, 2009.

[61] L. Chua, M. Lim, and B. Wong, "The Kunitz-protease inhibitor domain in amyloid precursor protein reduces cellular mitochondrial enzymes expression and function," Biochemical and Biophysical Research Communications, vol. 437, no. 4, pp. 642647, 2013.

[62] B. Sheng, X. Wang, B. Su et al., "Impaired mitochondrial biogenesis contributes to mitochondrial dysfunction in Alzheimer's disease," Journal of Neurochemistry, vol. 120, no. 3, pp. 419-429, 2012.

[63] M. Amiri and P. J. Hollenbeck, "Mitochondrial biogenesis in the axons of vertebrate peripheral neurons," Developmental Neurobiology, vol. 68, no. 11, pp. 1348-1361, 2008.

[64] X. Liu, D. Weaver, O. Shirihai, and G. Hajnóczky, "Mitochondrial kiss-and-run: Interplay between mitochondrial motility and fusion-fission dynamics," EMBO Journal, vol. 28, no. 20, pp. 3074-3089, 2009.

[65] H. Chen, S. A. Detmer, A. J. Ewald, E. E. Griffin, S. E. Fraser, and D. C. Chan, "Mitofusins Mfn1 and Mfn2 coordinately regulate mitochondrial fusion and are essential for embryonic development," Journal of Cell Biology, vol. 160, no. 2, pp. 189200, 2003.

[66] X. Wang, B. Su, S. L. Siedlak et al., "Amyloid- $\beta$ overproduction causes abnormal mitochondrial dynamics via differential modulation of mitochondrial fission/fusion proteins," Proceedings of the National Academy of Sciences of the United States of America, vol. 105, no. 49, pp. 19318-19323, 2008.

[67] X. Wang, B. Su, H. Fujioka, and X. Zhu, "Dynamin-like protein 1 reduction underlies mitochondrial morphology and distribution abnormalities in fibroblasts from sporadic Alzheimer's disease patients," The American Journal of Pathology, vol. 173, no. 2, pp. 470-482, 2008.
[68] M. Manczak and P. H. Reddy, "Abnormal interaction between the mitochondrial fission protein Drp1 and hyperphosphorylated tau in Alzheimer's disease neurons: Implications for mitochondrial dysfunction and neuronal damage," Human Molecular Genetics, vol. 21, no. 11, pp. 2538-2547, 2012.

[69] X. Wang, B. Su, H. Lee et al., "Impaired balance of mitochondrial fission and fusion in Alzheimer's disease," Journal of Neuroscience, vol. 29, no. 28, pp. 9090-9103, 2009.

[70] M. Manczak, M. J. Calkins, and P. H. Reddy, "Impaired mitochondrial dynamics and abnormal interaction of amyloid beta with mitochondrial protein Drp1 in neurons from patients with Alzheimer's disease: implications for neuronal damage," Human Molecular Genetics, vol. 20, no. 13, pp. 2495-2509, 2011.

[71] X. Wang, B. Su, S. L. Siedlak et al., "Amyloid- $\beta$ overproduction causes abnormal mitochondrial dynamics via differential modulation of mitochondrial fission/fusion proteins," Proceedings of the National Academy of Sciences of the United States of America, vol. 105, no. 49, pp. 19318-19323, 2008.

[72] Y. Tsujimoto and S. Shimizu, "Role of the mitochondrial membrane permeability transition in cell death," Apoptosis, vol. 12, no. 5, pp. 835-840, 2007.

[73] H. Du and S. S. Yan, "Mitochondrial permeability transition pore in Alzheimer's disease: cyclophilin D and amyloid beta," Biochimica et Biophysica Acta-Molecular Basis of Disease, vol. 1802, no. 1, pp. 198-204, 2010.

[74] V. K. Rao, E. A. Carlson, and S. S. Yan, "Mitochondrial permeability transition pore is a potential drug target for neurodegeneration," Biochimica et Biophysica Acta-Molecular Basis of Disease, vol. 1842, no. 8, pp. 1267-1272, 2014.

[75] J. W. Lustbader, M. Cirilli, C. Lin et al., "ABAD Directly Links A $\beta$ to Mitochondrial Toxicity in Alzheimer's Disease," Science, vol. 304, no. 5669, pp. 448-452, 2004.

[76] J. Hardy, "Amyloid, the presenilins and Alzheimer's disease," Trends in Neurosciences, vol. 20, no. 4, pp. 154-159, 1997.

[77] Y. Yan, Y. Liu, M. Sorci et al., "Surface plasmon resonance and nuclear magnetic resonance studies of ABAD-A $\beta$ interaction," Biochemistry, vol. 46, no. 7, pp. 1724-1731, 2007.

[78] J. Yao, H. Du, and S. Yan, "Inhibition of amyloid- $\beta(\mathrm{A} \beta)$ peptidebinding alcohol dehydrogenase- $\mathrm{A} \beta$ interaction reduces $\mathrm{A} \beta$ accumulation and improves mitochondrial function in a mouse model of alzheimer's disease," The Journal of Neuroscience, vol. 31, no. 6, pp. 2313-2320, 2011.

[79] Y. Ren, W. X. Hong, F. Davey et al., "Endophilin I expression is increased in the brains of Alzheimer disease patients," The Journal of Biological Chemistry, vol. 283, no. 9, pp. 5685-5691, 2008.

[80] J. Yao, M. Taylor, F. Davey et al., "Interaction of amyloid binding alcohol dehydrogenase/A $\beta$ mediates up-regulation of peroxiredoxin II in the brains of Alzheimer's disease patients and a transgenic Alzheimer's disease mouse model," Molecular and Cellular Neuroscience, vol. 35, no. 2, pp. 377-382, 2007.

[81] A. R. Ramjaun, A. Angers, V. Legendre-Guillemin, X. Tong, and P. S. McPherson, "Endophilin regulates JNK activation through its interaction with the germinal center kinase-like kinase," Journal of Biological Chemistry, vol. 276, no. 31, pp. 28913-28919, 2001.

[82] A. Colombo, A. Bastone, C. Ploia et al., "JNK regulates APP cleavage and degradation in a model of Alzheimer's disease," Neurobiology of Disease, vol. 33, no. 3, pp. 518-525, 2009.

[83] A. Falkevall, N. Alikhani, S. Bhushan et al., "Degradation of the amyloid $\beta$-protein by the novel mitochondrial peptidasome, 
PreP," Journal of Biological Chemistry, vol. 281, no. 39, pp. 2909629104, 2006.

[84] N. Alikhani, M. Ankarcrona, and E. Glaser, "Mitochondria and Alzheimer's disease: amyloid- $\beta$ peptide uptake and degradation by the presequence protease, hPreP," Journal of Bioenergetics and Biomembranes, vol. 41, no. 5, pp. 447-451, 2009.

[85] N. Alikhani, L. Guo, S. Yan et al., "Decreased proteolytic activity of the mitochondrial amyloid- $\beta$ degrading enzyme, PreP peptidasome, in Alzheimer's disease brain mitochondria," Journal of Alzheimer's Disease, vol. 27, no. 1, pp. 75-87, 2011.

[86] P. Filipe Teixeira, C. Moreira Pinho, R. M. Branca, J. Lehtiö, R. L. Levine, and E. Glaser, "In vitro oxidative inactivation of human presequence protease (hPreP)," Free Radical Biology and Medicine, vol. 53, no. 11, pp. 2188-2195, 2012.

[87] C. Schmidt, E. Lepsverdize, S. L. Chi et al., "Amyloid precursor protein and amyloid $\beta$-peptide bind to ATP synthase and regulate its activity at the surface of neural cells," Molecular Psychiatry, vol. 13, no. 10, pp. 953-969, 2008.

[88] S. Hauptmann, I. Scherping, S. Dröse et al., "Mitochondrial dysfunction: an early event in Alzheimer pathology accumulates with age in AD transgenic mice," Neurobiology of Aging, vol. 30, no. 10, pp. 1574-1586, 2009.

[89] V. Rhein, G. Baysang, S. Rao et al., "Amyloid-beta leads to impaired cellular respiration, energy production and mitochondrial electron chain complex activities in human neuroblastoma cells," Cellular and Molecular Neurobiology, vol. 29, no. 6-7, pp. 1063-1071, 2009.

[90] A. Bobba, G. Amadoro, D. Valenti, V. Corsetti, R. Lassandro, and A. Atlante, "Mitochondrial respiratory chain Complexes I and IV are impaired by $\beta$-amyloid via direct interaction and through Complex I-dependent ROS production, respectively," Mitochondrion, vol. 13, no. 4, pp. 298-311, 2013.

[91] D. Praticò, "Oxidative stress hypothesis in Alzheimer's disease: a reappraisal," Trends in Pharmacological Sciences, vol. 29, no. 12, pp. 609-615, 2008.

[92] R. K. Chaturvedi and M. F. Beal, "Mitochondrial approaches for neuroprotection," Annals of the New York Academy of Sciences, vol. 1147, pp. 395-412, 2008.

[93] R. A. J. Smith, V. J. Adlam, F. H. Blaikie et al., "Mitochondriatargeted antioxidants in the treatment of disease," Annals of the New York Academy of Sciences, vol. 1147, pp. 105-111, 2008.

[94] D. Pratico, "Evidence of oxidative stress in Alzheimers disease brain and antioxidant therapy: lights and shadows," Annals of the New York Academy of Sciences, vol. 1147, pp. 70-78, 2008.

[95] H. H. Szeto, "Development of mitochondria-targeted aromaticcationic peptides for neurodegenerative diseases," Annals of the New York Academy of Sciences, vol. 1147, pp. 112-121, 2008.

[96] M. Manczak, P. Mao, M. J. Calkins et al., "Mitochondriatargeted antioxidants protect against amyloid- $\beta$ toxicity in Alzheimer's disease neurons," Journal of Alzheimer's Disease, vol. 20, no. 2, pp. S609-S631, 2010.

[97] P. H. Reddy, R. Tripathi, Q. Troung et al., "Abnormal mitochondrial dynamics and synaptic degeneration as early events in Alzheimer's disease: implications to mitochondria-targeted antioxidant therapeutics," Biochimica et Biophysica Acta: Molecular Basis of Disease, vol. 1822, no. 5, pp. 639-649, 2012.

[98] J. S. Tauskela, "MitoQ—a mitochondria-targeted antioxidant," IDrugs, vol. 10, no. 6, pp. 399-412, 2007.

[99] M. F. Ross, T. A. Prime, I. Abakumova et al., "Rapid and extensive uptake and activation of hydrophobic triphenylphosphonium cations within cells," Biochemical Journal, vol. 411, no. 3, pp. 633-645, 2008.
[100] A. Azzi, "Oxidative stress: a dead end or a laboratory hypothesis?" Biochemical and Biophysical Research Communications, vol. 362, no. 2, pp. 230-232, 2007.

[101] X. Gan, S. Huang, L. Wu et al., "Inhibition of ERK-DLP1 signaling and mitochondrial division alleviates mitochondrial dysfunction in Alzheimer's disease cybrid cell," Biochimica et Biophysica Acta-Molecular Basis of Disease, vol. 1842, no. 2, pp. 220-231, 2014.

[102] Y. Zhao and B. Zhao, "Natural antioxidants in prevention and management of Alzheimer's disease," Frontiers in Bioscience (Elite edition), vol. 4, pp. 794-808, 2012.

[103] G. P. Lim, T. Chu, F. Yang, W. Beech, S. A. Frautschy, and G. M. Cole, "The curry spice curcumin reduces oxidative damage and amyloid pathology in an Alzheimer transgenic mouse," Journal of Neuroscience, vol. 21, no. 21, pp. 8370-8377, 2001.

[104] S. A. Frautschy, W. Hu, P. Kim et al., "Phenolic antiinflammatory antioxidant reversal of $\mathrm{A} \beta$-induced cognitive deficits and neuropathology," Neurobiology of Aging, vol. 22, no. 6, pp. 993-1005, 2001.

[105] F. Yang, G. P. Lim, A. N. Begum et al., "Curcumin inhibits formation of amyloid $\beta$ oligomers and fibrils, binds plaques, and reduces amyloid in vivo," The Journal of Biological Chemistry, vol. 280, no. 7, pp. 5892-5901, 2005.

[106] L. Baum, C. W. K. Lam, S. K. Cheung et al., "Six-month randomized, placebo-controlled, double-blind, pilot clinical trial of curcumin in patients with Alzheimer disease," Journal of Clinical Psychopharmacology, vol. 28, no. 1, pp. 110-113, 2008.

[107] S. Marrache and S. Dhar, "Engineering of blended nanoparticle platform for delivery of mitochondria-acting therapeutics," Proceedings of the National Academy of Sciences of the United States of America, vol. 109, no. 40, pp. 16288-16293, 2012.

[108] R. Abdel-Kader, S. Hauptmann, U. Keil et al., "Stabilization of mitochondrial function by Ginkgo biloba extract (EGb 761)," Pharmacological Research, vol. 56, no. 6, pp. 493-502, 2007.

[109] V. Rhein, M. Giese, G. Baysang et al., "Ginkgo biloba extract ameliorates oxidative phosphorylation performance and rescues A $\beta$-induced failure," PLoS ONE, vol. 5, no. 8, Article ID e12359, 2010. 


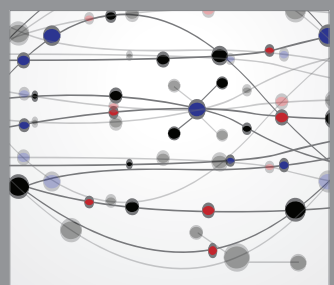

The Scientific World Journal
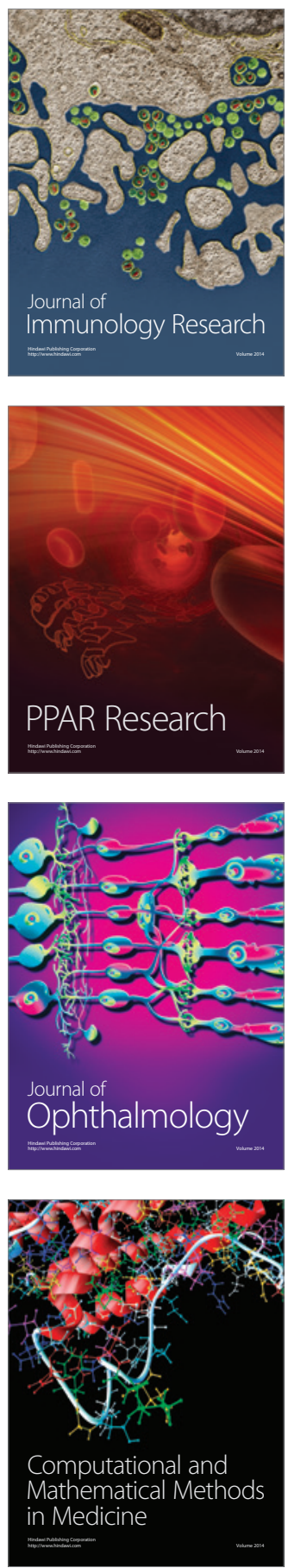

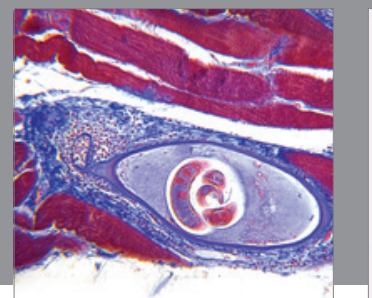

Gastroenterology

Research and Practice
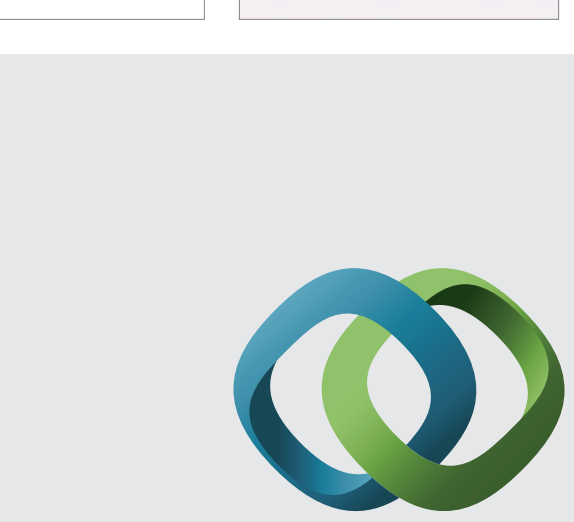

\section{Hindawi}

Submit your manuscripts at

http://www.hindawi.com
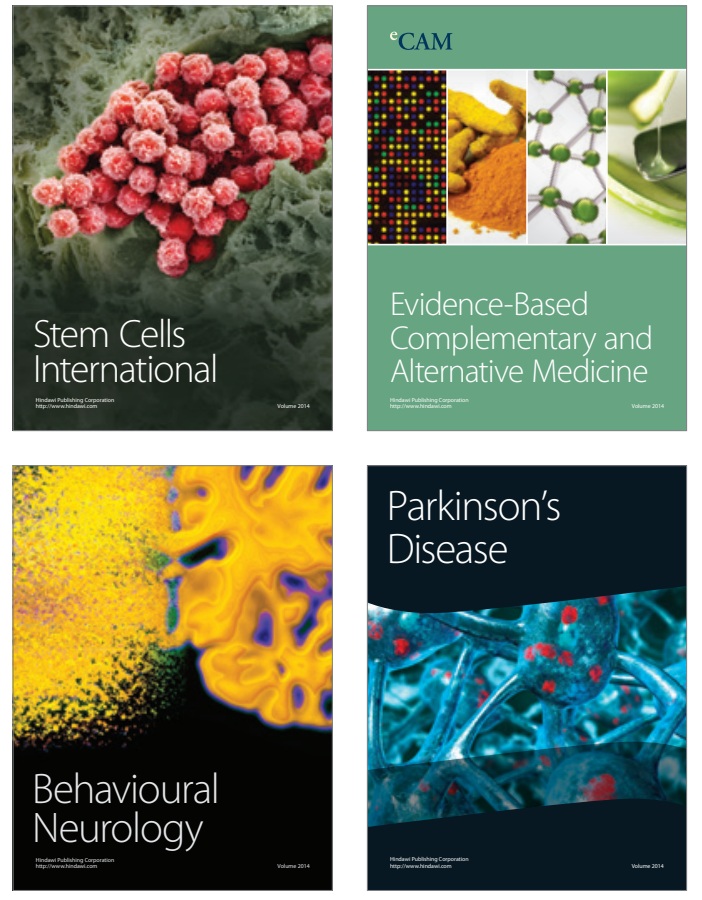
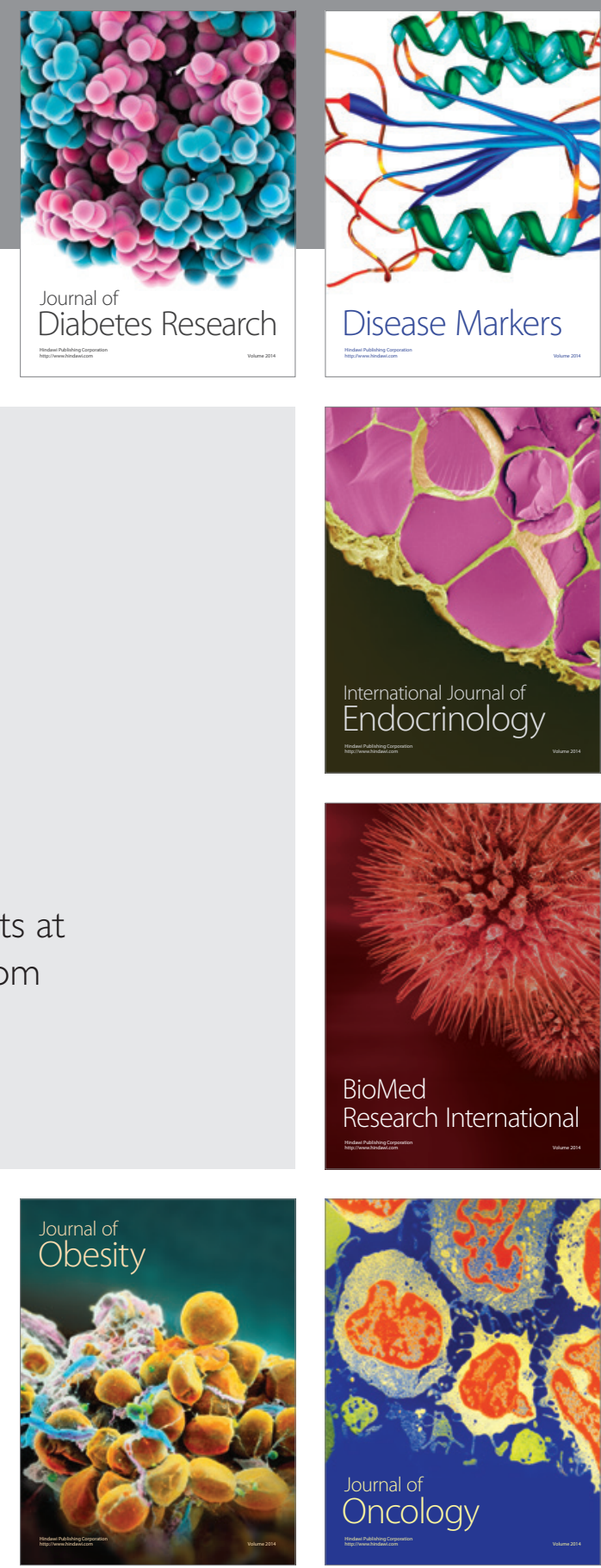

Disease Markers
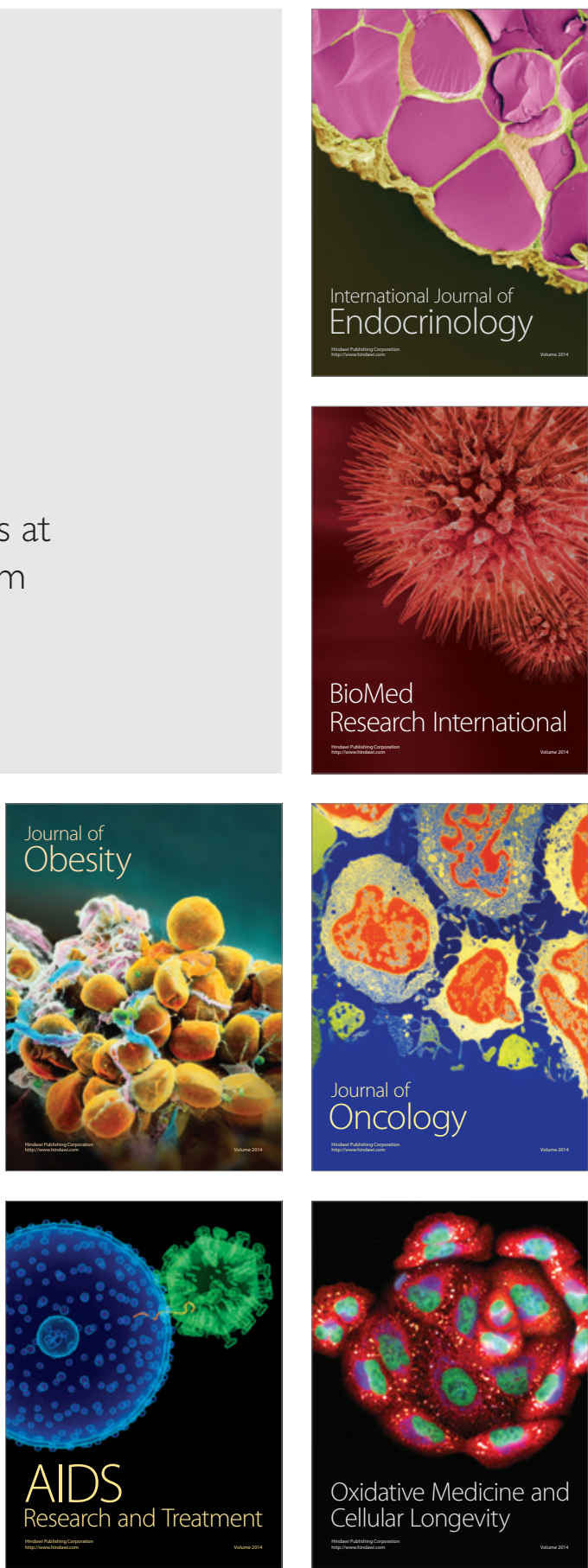